\title{
Ionospheric Day-to-Day Variability Around the Whole Heliosphere Interval in 2008
}

\author{
Wenbin Wang • Jiuhou Lei · Alan G. Burns • \\ Liying Qian · Stanley C. Solomon • Michael Wiltberger • \\ Jiyao Xu
}

Received: 17 June 2010 / Accepted: 23 February 2011 / Published online: 29 April 2011

(C) Springer Science+Business Media B.V. 2011

\begin{abstract}
Ionospheric F2 peak electron densities (NmF2) measured at ten ionosonde stations have been analyzed to investigate ionospheric day-to-day variability around the Whole Heliosphere Interval (WHI) in 2008 (Day of Year (DOY) 50-140). The ionosonde data showed that there was significant global day-to-day variability in NmF2. This variability had 5-, 7-, 9-, 11-, 13.5-, and 16-21-day periodicities. At middle latitudes, the ionosphere appeared to respond directly to the solar-wind and interplanetary-magnetic-field (IMF) induced geomagnetic-activity forcing, with the day-to-day variability having the same periods as those in the solar-wind/IMF and geomagnetic activity. At the geomagnetic Equator, the ionosphere had a strong 7-day periodicity, corresponding to the same periodicity in the IMF $B_{z}$ component. In the equatorial anomaly region, the ionosphere showed more complicated day-to-day variability, dominated by the 9 -day periodicity. In addition, there were also peri-
\end{abstract}

The Sun-Earth Connection near Solar Minimum

Guest Editors: M.M. Bisi, B. Emery, and B.J. Thompson.

W. Wang $(\bowtie) \cdot$ A.G. Burns · L. Qian · S.C. Solomon · M. Wiltberger

High Altitude Observatory, National Center for Atmospheric Research, Boulder, CO, USA

e-mail: wbwang@ucar.edu

A.G. Burns

e-mail: aburns@ucar.edu

L. Qian

e-mail: Iqian@ucar.edu

S.C. Solomon

e-mail: stans@ucar.edu

M. Wiltberger

e-mail: wiltbemj@ucar.edu

J. Lei

Department of Aerospace Engineering Sciences, University of Colorado, Boulder, CO, USA

e-mail: Jiuhou.lei@colorado.edu

J. Xu

Center for Space Science and Applied Research, Chinese Academy of Sciences, Beijing, China

e-mail: xujy@cssar.ac.cn 
odicities of 11 days and 16-21 days in the ionosonde data at some stations. The ionosonde data were compared with the Coupled Magnetosphere Ionosphere Thermosphere (CMIT) simulations that were driven by the observed solar-wind and IMF data during the WHI. The CMIT simulations showed similar ionospheric daily variability seen in the data. They captured the positive and negative responses of the ionosphere at middle latitudes during the first corotating interaction region (CIR) event in the WHI. The response of the model to the second CIR event, however, was relatively weak.

\section{Introduction}

The Earth's ionosphere has significant day-to-day variability over a wide range of time scales. Part of this variability, which is caused by solar zenith angle changes with local time and season, is well understood. On top of this regular, well behaved mean state of the ionosphere, there exist considerable daily variations under both quiet and disturbed geomagnetic conditions. For instance, Rishbeth and Mendillo (2001) found that for medium solar activity the fluctuations of the ionospheric peak electron density $(\mathrm{NmF} 2)$ have a standard deviation of $20 \%$ in the daytime and $33 \%$ at night time. Forbes, Palo, and Zhang (2000), using data from over 100 ionosonde stations, showed that under very quiet conditions $(\mathrm{Kp}<1)$, the standard deviation or $1-\sigma$ variability of $\mathrm{NmF} 2$ around the mean was about $25-35 \%$ at high frequencies (periods of a few hours to 1 to 2 days) and about $15-20 \%$ at low frequencies (periods of 2-30 days) at all latitudes.

Rishbeth and Mendillo (2001) and many others have suggested that the causes of this ionospheric variability are external: variations in solar EUV and X-ray fluxes (solar radiation), changes in solar-wind and interplanetary-magnetic-field (IMF) conditions (geomagnetic), and large-scale lower-atmospheric waves (meteorological). They found that the "solar-radiation" component is a minor contributor to the ionospheric daily variability, a conclusion that is consistent with that of Forbes, Palo, and Zhang (2000). These studies did not include NmF2 changes with solar rotation. Correlation studies showed that there are distinct peaks of ionospheric variability around 27 and 13.5 days that are related to the changes of solar radiation and solar wind with the 27-day solar-rotation period and its half-period harmonics (Altadill and Apostolov, 2003).

Rishbeth and Mendillo (2001) also found that the "meteorological" sources of the ionospheric variability are comparable to the "geomagnetic" sources. Xiong et al. (2006) also tried to separate the ionosonde-observed ionospheric-variability events that are correlated with "meteorological" sources from those with "geomagnetic" sources. They found that ionospheric variability events with periods of 5, 10, and 13.5 days are most likely associated with geomagnetic activity. There is strong evidence that solar-wind density, speed, and temperature, as well as IMF parameters have strong day-to-day variability (Mursula and Zieger, 1996). The variability in the solar wind/IMF produces changes in the high-latitude convection electric field and auroral precipitation (Codrescu, Fuller-Rowell, and Foster, 1995) which, in turn, results in changes in global thermospheric composition and wind circulation, and thus alters electron-density profiles even during non-disturbed conditions (see, e.g., Mayr, Harris, and Spencer, 1978; Wang et al., 2008b). Furthermore, high-latitude electric fields can also penetrate directly into middle and low latitudes causing changes in electron densities (see, e.g., Wang et al., 2010).

The Whole Heliosphere Interval (WHI: DOY $84-111,2008$ ) had a vast array of variations of different time scales in the properties of solar wind and IMF. They are associated with the high-speed streams and corotating interaction regions (CIRs) (see, e.g., Gibson et 
Table 1 Ionosonde stations used in the analysis.

\begin{tabular}{lcccc}
\hline Station & $\begin{array}{l}\text { Geographic } \\
\text { Latitude }\end{array}$ & $\begin{array}{l}\text { Geographic } \\
\text { Longitude }\end{array}$ & $\begin{array}{l}\text { Geomagnetic } \\
\text { Latitude }\end{array}$ & $\begin{array}{l}\text { Geomagnetic } \\
\text { Longitude }\end{array}$ \\
\hline Jicamarca & -12 & -76.8 & 0.29 & -4.9 \\
Kwajalien & 9 & 167.2 & 4.3 & -121.5 \\
Ascension & -7.9 & -14.4 & -19.5 & 53.7 \\
Darwin & -12.5 & 131 & -21.4 & -156.3 \\
El Arenosilla & 37.1 & -6.7 & 30.2 & 68 \\
Boulder & 40 & -105.3 & 48.5 & -40.3 \\
Camden & -34 & 150.7 & -43.4 & -131.3 \\
Juliusruh & 54.6 & 13.4 & 50.7 & 89.6 \\
Millstone Hill & 42.6 & -71.5 & 51.8 & 7.3 \\
Point Arguello & 35.6 & -120.6 & 40.9 & -56.8 \\
\hline
\end{tabular}

al., 2009; Lei et al., 2011) that were the dominant features during the declining and minimum phases of Solar Cycle 23. Lei et al. (2008a, and references therein) showed that thermospheric mass-density perturbations with multi-day periods were the results of high-speed streams and CIRs during the declining phase of Solar Cycle 23. They further showed that global mean ionospheric total electron content (TEC) also had 7- and 9-day periodicities that were evidently also associated with high-speed streams and CIR events (Lei et al., 2008b).

In this article, we will investigate ionospheric day-to-day variability that is associated with geomagnetic activity caused by solar-wind and IMF variations around the WHI when solar activity was extremely low. This makes WHI an ideal time period for examining ionospheric day-to-day variability not associated with changes in solar radiation. We also study changes of this ionospheric day-to-day variability with geomagnetic latitudes. In Section 2, we describe the data sets used in this study, followed by a detailed presentation of the results in Section 3. Comparisons between data and numerical results by the Coupled Magnetosphere Ionosphere and Thermosphere (CMIT) model during the WHI are presented in Section 4. Discussion of the results will be given in Section 5. Finally, in Section 6 we present our conclusions.

\section{Data Sets}

The ionosonde data used in this study are obtained from the US National Geophysical Data Center (NGDC) Web site (http://spidr.ngdc.noaa.gov/spidr/). The geographic and geomagnetic locations of these stations are given in Table 1. Data from these stations were mostly complete or with small data gaps around the WHI. Thus, in our spectral analysis we used the Lomb-Scargle periodogram which gives an estimate of the power spectrum of unevenly sampled data (Lomb, 1976; Scargle, 1982; Horne and Baliunas, 1986; Weber et al., 1999). The ionosonde data at three stations (Camden, Darwin, and Juliusruh) are manually verified data. Data for other ionosonde stations are obtained by automatic computer-scaling programs. We examined all data sets and found that they were consistent from day to day. Since the WHI only covered one solar rotation of 27 days (CR 2068), aliasing in spectral analysis can occur for variability that has periods of 9 days or longer. Thus, we use data from DOY 50-140, 2008, covering three consecutive solar rotations. 

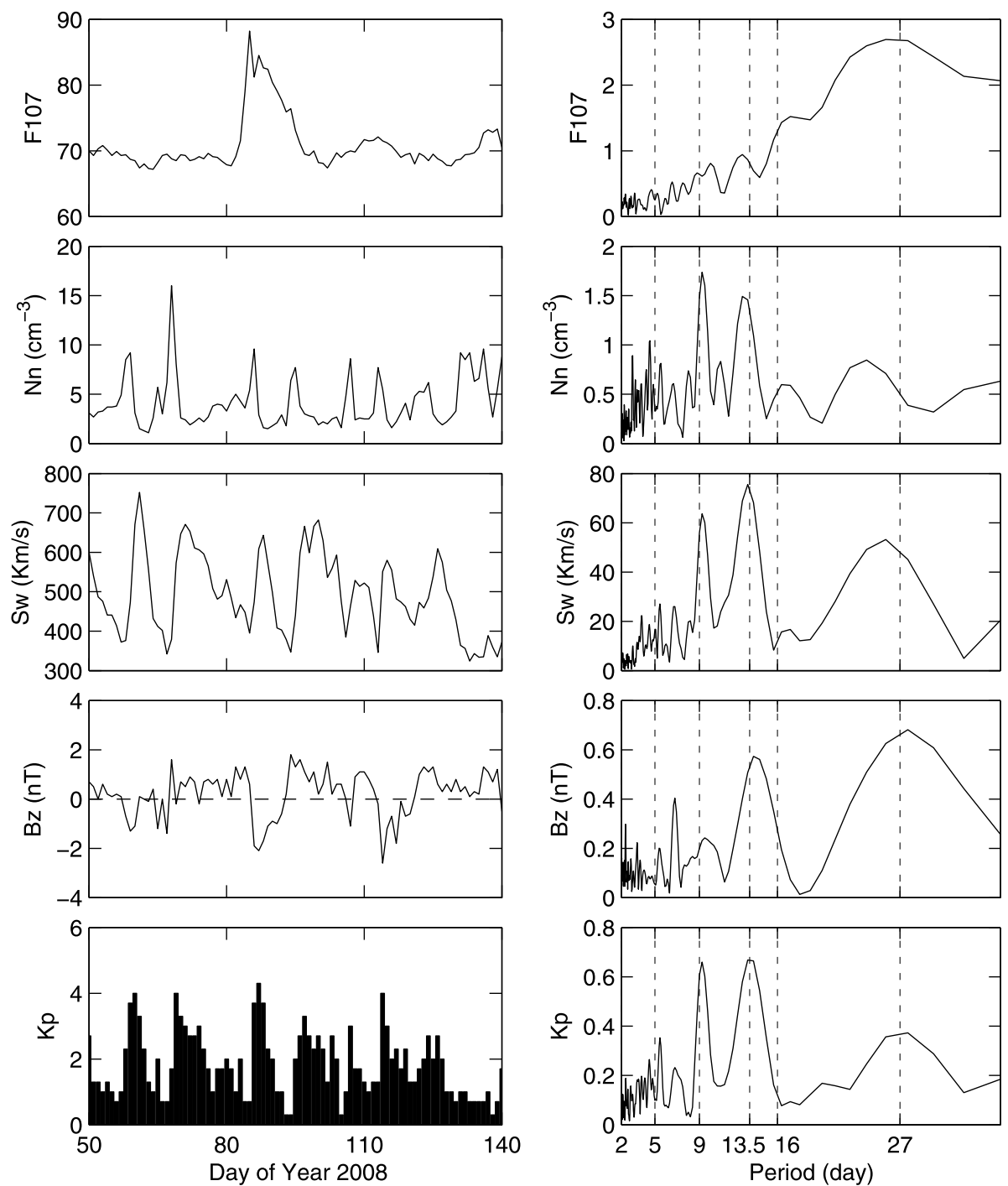

Figure 1 (Left-hand panels, from top to bottom) Variations of $\mathrm{F}_{10.7}$, solar-wind density $\left(N_{n}, \mathrm{~cm}^{-3}\right)$, solar-wind speed $\left(\mathrm{km} \mathrm{s}^{-1}\right)$, IMF $B_{z}$ component in GSM (nT), and geomagnetic activity index Kp for DOY $50-140$ in 2008. (Right-hand panels, from top to bottom) Lomb-Scargle spectra of $\mathrm{F}_{10.7}$, solar-wind density, solar-wind speed, IMF $B_{z}$ component in GSM, and geomagnetic activity index $\mathrm{Kp}$ for the same period.

In addition, these stations are separated into three groups based on their geomagnetic latitudes: geomagnetic equatorial stations (Jicamarca and Kwajalien), equatorial-anomaly stations (Ascension, Darwin, and El Arenosilla), and geomagnetic middle latitudes (Boulder, Camden, Juliusruh, Millstone Hill, and Point Arguello).

The geophysical conditions around the WHI obtained from the OMNI database (http://omniweb.gsfc.nasa.gov) are shown in Figure 1. The left-hand panels in Figure 1 from top to bottom give daily averaged solar $10.7 \mathrm{~cm}$ radio flux $\left(\mathrm{F}_{10.7}\right)$, solar-wind density, solarwind speed, IMF $B_{z}$, and the Kp index for DOY 50-140 in 2008 with the WHI being in the 
middle of the period. The daily averaged data are used since we are interested in day-to-day variability so variations with periods less than a day are not important to this paper. The right-hand panels in Figure 1 give Lomb-Scargle spectra and their absolute amplitudes of the corresponding parameters. $F_{10.7}$ had just one peak at the beginning of the WHI. There were no evident spectral peaks in $\mathrm{F}_{10.7}$ with periods less than 27 days. Both solar-wind speed and density had recurrent features. The peaks in solar-wind speed occurred immediately after the peaks of solar-wind number density. The IMF component on the other hand oscillated with an amplitude of about 2-4 nT. These are the typical signatures of high-speed streams and CIR events (see, e.g., Tsurutani et al., 1995, 2006).

Moderate geomagnetic activity $(\mathrm{Kp}>3)$ occurred during the WHI. The peaks of Kp corresponded to those of the solar-wind density and speed, indicating that geomagnetic activity was mostly caused by CIR events. The 13.5-day spectral peaks were seen in all fields, although it was not strong in $\mathrm{F}_{10.7}$. The $\mathrm{Kp}$ index had a strong 9-day period peak, which was also seen in the Lomb-Scargle spectra of solar-wind speed and density. There were also two secondary peaks in the Kp spectrum with 5-day and 7-day periods. The 5-day peak of Kp corresponded to those in both the solar-wind and IMF $B_{z}$, whereas the 7-day peak appeared to be mostly related to that of $B_{z}$.

\section{Results}

In this section we present ionospheric peak density variations observed at ten ionosonde stations around the WHI. Figure 2 shows ionosonde measured NmF2 (left-hand panels, hourly averaged data) and their Lomb-Scargle spectra (right-hand panels) between DOY 50 and DOY 140 in 2008 for five geomagnetic middle latitude stations: Boulder, Camden, Juliusruh, Millstone Hill, and Point Arguello. Large day-to-day variability in NmF2 is evident at all stations. In Figure 2 and other similar spectral figures, we exclude the strong diurnal peak in the spectra since it is well understood and not the topic of this paper.

There were clear 8-10-day, centered at 9-day, periodicities in NmF2 at all five middle latitude stations. The $8-10$ day periodicities in $\mathrm{NmF} 2$ were clearly related to the same periodicities in solar-wind density, speed, and consequently, in the Kp index shown in Figure 1. With the exception of Camden, all other four stations also had NmF2 variations at the 7-day period. This 7-day periodicity is probably related to the variations in IMF $B_{z}$ at the same frequency. Four-five-day variations are also seen in $\mathrm{NmF} 2$ at all stations which also occurred in the solar-wind, IMF, and Kp data.

Peaks in the spectra with a period of about 13.5 days occurred for all stations, corresponding well to the peaks seen in solar-wind density, speed, $B_{z}$, and the $\mathrm{Kp}$ index indicating that ionospheric $\mathrm{NmF} 2$ responded to the 13.5-day periodicities in high-latitude driving conditions. In addition, periodicities of 16-21 days occurred at four stations: Boulder, Juliusruh, Millstone Hill, and Point Arguello. There was no evidence of these periodicities in the solarwind, IMF $B_{z}$, and Kp data, suggesting that they were probably not related to solar-wind and geomagnetic-activity conditions.

Thus, at geomagnetic middle latitudes, 16-21-, 13.5-, 9-, 7-, and 5-day spectral peaks occurred at most of the stations. All these peaks, with the exception of the 16-21-day peak, found their corresponding peaks in the solar-wind, IMF $B_{z}$, and $\mathrm{Kp}$ data, indicating the correlation between the daily variations of the ionospheric electron density and the solarwind/IMF and geomagnetic activity driving conditions.

Figure 3, in the same format as that in Figure 2, gives ionosonde-observed NmF2 (lefthand panels) and their Lomb-Scargle spectra (right-hand panels) at three equatorial anomaly 

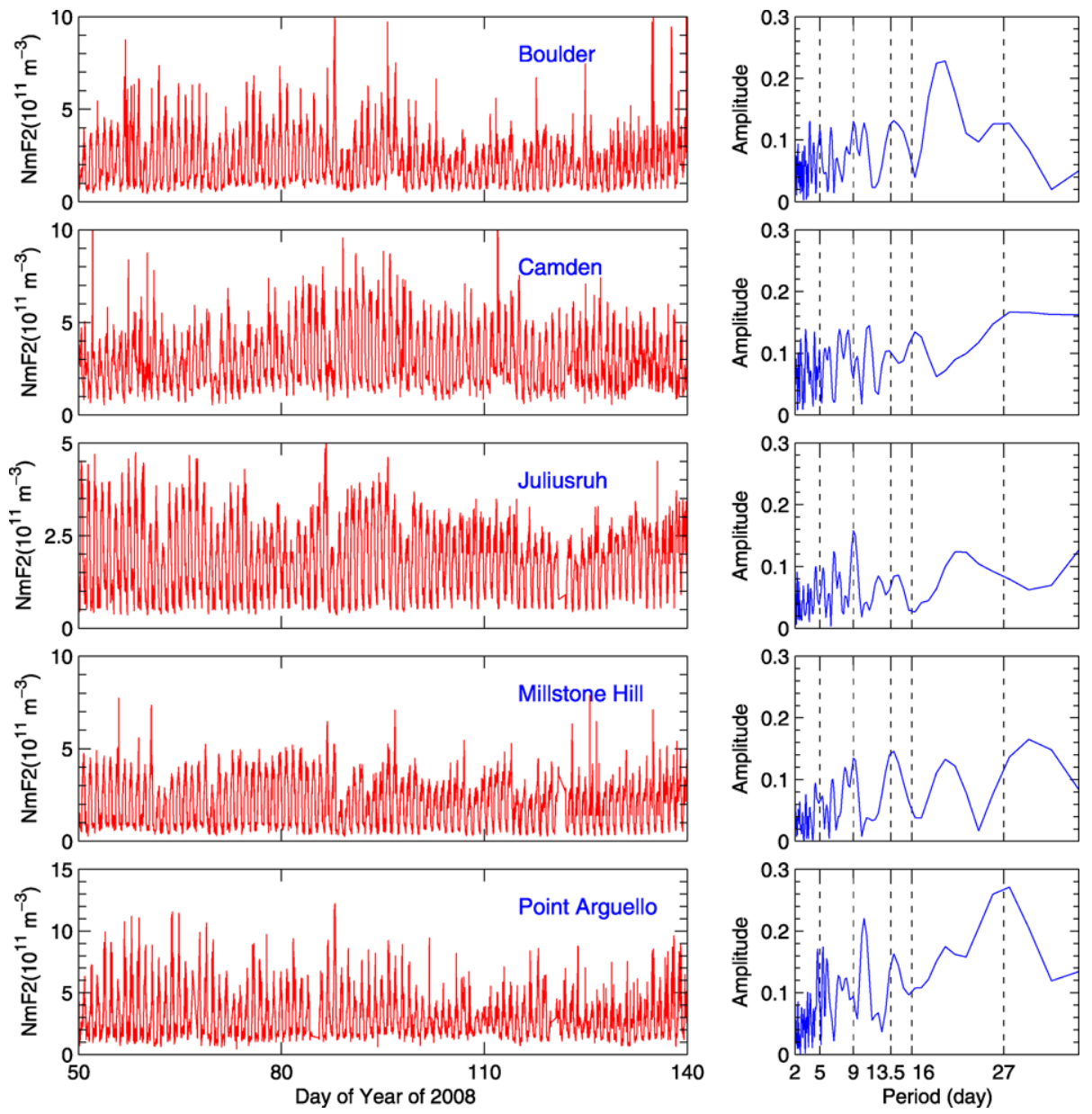

Figure 2 Ionospheric F2 peak densities (left-hand panels) and their Lomb-Scargle spectra (right-hand panels) at magnetic middle latitude ionosonde stations (from top to bottom): Boulder, Camden, Juliusruh, Millstone Hill, and Point Arguello between DOY 50 and DOY 140 in 2008.

stations: Ascension, Darwin, and El Arenosilla. There were evident 9-day spectral peaks in $\mathrm{NmF} 2$ at all three stations, which is similar to that at magnetic middle latitude stations. However, the spectral peaks with periodicities of 16-21 days occurred only at one station (Darwin), and the 13.5-day spectral peak was not seen in any of these three stations. Instead, spectral peaks with period close to 14.5-day occurred at Ascension and El Arenosilla, whereas at Darwin there was only one dominant peak with an 18-day period. It is also interesting to note that at all three stations, there was a peak with an 11-day period, which is not seen in middle latitude observations, nor was it present in the solar-wind/IMF and Kp data. In addition, 5- and 7-day spectral peaks were not as evident as those at the middle latitude stations.

The measured $\mathrm{NmF} 2$ and the corresponding Lomb-Scargle spectra at two magnetic equatorial stations (Jicamarca and Kwajalein) are shown in Figure 4. Spectral peaks with periods of about $4-5,7,9$, and 13.5 days are seen in these two stations. 16-21 day spectral peaks 

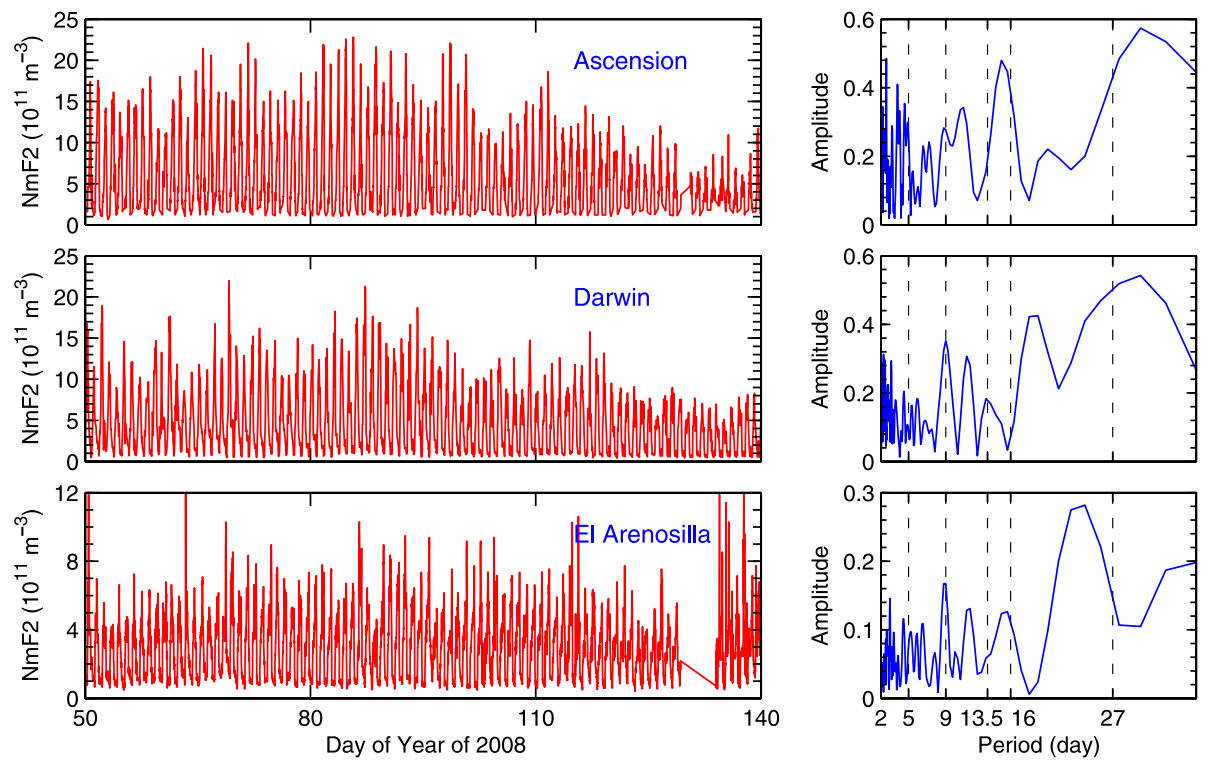

Figure 3 Ionospheric F2 peak densities (left-hand panels) and their Lomb-Scargle spectra (right-hand panels) at equatorial-anomaly stations: Acension, Darwen, and El Arenosilla between DOY 50 and DOY 140 in 2008.
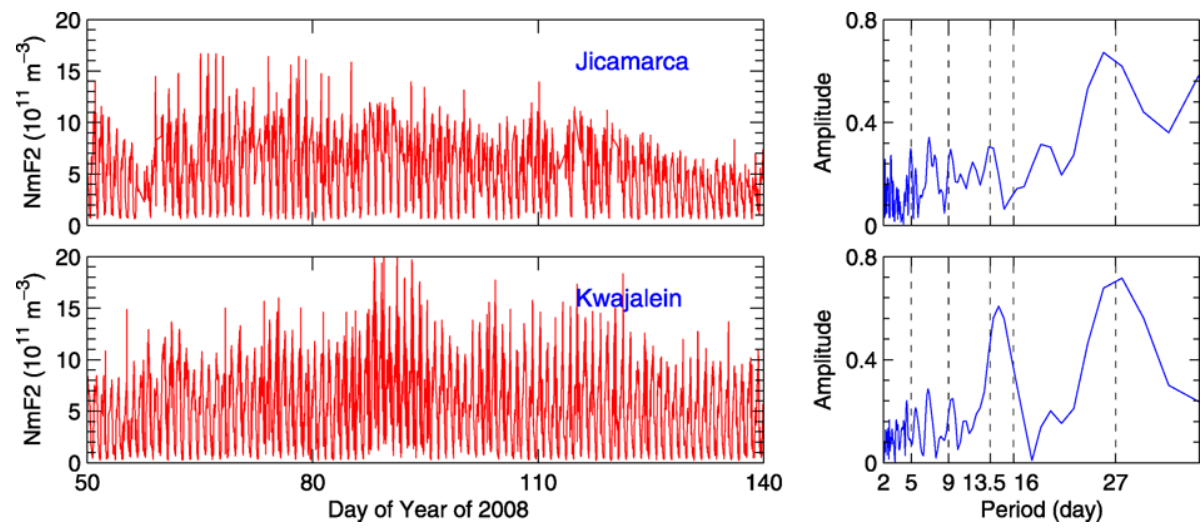

Figure 4 Ionospheric F2 peak densities (left-hand panels) and their Lomb-Scargle spectra (right-hand panels) at magnetic equatorial ionosonde stations: Jicamarca and Kwajalein between DOY 50 and DOY 140 in 2008.

occurred at Jicamarca, but not at Kwajalein. There was no 11-day variation at either station. Furthermore, compared to stations in the magnetic middle-latitude and equatorial-anomaly regions, $\mathrm{NmF} 2$ at the magnetic Equator appears to have stronger 7-day and weaker 9-day spectral peaks.

Thus, there were similarities and differences in the day-to-day variability in the ionospheric F2 peak electron densities at different latitudes. Table 2 summarizes ionospheric day-to-day variability seen during a 90-day period around the WHI in 2008. A 9-day spectral peak occurred at almost all stations, whereas spectral peaks with other frequencies may 
Table 2 Ionospheric day-to-day variability at different stations ${ }^{\mathrm{a}}$.

\begin{tabular}{lllllll}
\hline Station/Period (days) & $4-5$ & 7 & 9 & 11 & 13.5 & $16-21$ \\
\hline Jicamarca & $\mathrm{M}$ & $\mathrm{S}$ & $\mathrm{M}$ & $\mathrm{N}$ & $\mathrm{M}$ & $\mathrm{M}$ \\
Kwajalien & $\mathrm{M}$ & $\mathrm{S}$ & $\mathrm{M}$ & $\mathrm{N}$ & $\mathrm{S}$ & $\mathrm{N}$ \\
Ascension & $\mathrm{M}$ & $\mathrm{W}$ & $\mathrm{M}$ & $\mathrm{M}$ & $\mathrm{N}$ & $\mathrm{N}$ \\
Darwin & $\mathrm{N}$ & $\mathrm{N}$ & $\mathrm{S}$ & $\mathrm{M}$ & $\mathrm{N}$ & $\mathrm{S}$ \\
El Arenosilla & $\mathrm{N}$ & $\mathrm{N}$ & $\mathrm{S}$ & $\mathrm{M}$ & $\mathrm{N}$ & $\mathrm{N}$ \\
Boulder & $\mathrm{M}$ & $\mathrm{M}$ & $\mathrm{M}$ & $\mathrm{N}$ & $\mathrm{M}$ & $\mathrm{S}$ \\
Camden & $\mathrm{W}$ & $\mathrm{N}$ & $\mathrm{M}$ & $\mathrm{M}$ & $\mathrm{W}$ & $\mathrm{N}$ \\
Juliusruh & $\mathrm{W}$ & $\mathrm{M}$ & $\mathrm{S}$ & $\mathrm{N}$ & $\mathrm{M}$ & $\mathrm{M}$ \\
Millstone Hill & $\mathrm{W}$ & $\mathrm{M}$ & $\mathrm{S}$ & $\mathrm{N}$ & $\mathrm{S}$ & $\mathrm{M}$ \\
Point Arguello & $\mathrm{S}$ & $\mathrm{M}$ & $\mathrm{S}$ & $\mathrm{N}$ & $\mathrm{M}$ & $\mathrm{M}$ \\
\hline
\end{tabular}

${ }^{a}$ M: medium variability; S: Strong variability; W: Weak variability, N: No variability.

occur only at some stations. Some of the spectral peaks had periods that are not seen in solar-wind/IMF and geomagnetic activity driving conditions, indicating that the ionospheric day-to-day variability is the result of a more-complicated process. This process probably involves sources not only from changes in high-latitude inputs caused by solar-wind and IMF driving conditions, but also from planetary waves from the lower atmosphere as well as the nonlinear interaction between these processes. The planetary waves can affect the F-region ionosphere through the modification of both background winds and tides, and consequently, the E-region dynamo and F-region ionosphere (Liu et al., 2010).

\section{Model Simulations}

In this section, we present numerical simulations of the global thermosphere and ionosphere during the WHI using the CMIT model. A detailed description of the CMIT model can be found in Luhmann et al. (2004), Wiltberger et al. (2004), and Wang et al. (2004, 2008a). In short, the CMIT model couples the Lyon-Fedder-Mobarry (LFM) global magnetosphere MHD code (Lyon, Fedder, and Mobarry, 2004) with the Thermosphere Ionosphere Electrodynamics General Circulation Model (TIEGCM) (Richmond, Ridley, and Roble, 1992). The coupling between the magnetospheric global MHD codes with the thermosphereionosphere global-circulation models (GCMs) replaces empirical models of high-latitude convection electric field and auroral precipitation, which are normally specified for the GCMs using empirical models, with self-consistently calculated parameters from the coupled model. This enables studies of the dynamical coupling between the magnetosphere and ionosphere and the impact of the solar wind/magnetosphere on the ionosphere variability to be made. In this study, the CMIT model was run between DOY 80 and DOY 107 using observed solar-wind and IMF data (Figure 1) as the model driver. We also used a constant value of $\mathrm{F}_{10.7}(70)$ to specify the solar-radiation condition for the model. Thus, the model simulation did not include the effect of the $\mathrm{F}_{10.7}$ peak during the WHI. In addition, the model run did not extend to include the third CIR event occurring after DOY107 because of the computation cost.

Figure 5 shows ionosonde-observed NmF2 (black lines with open circles) and CMITsimulated NmF2 (blue lines) at Millstone Hill representing the magnetic middle latitude 

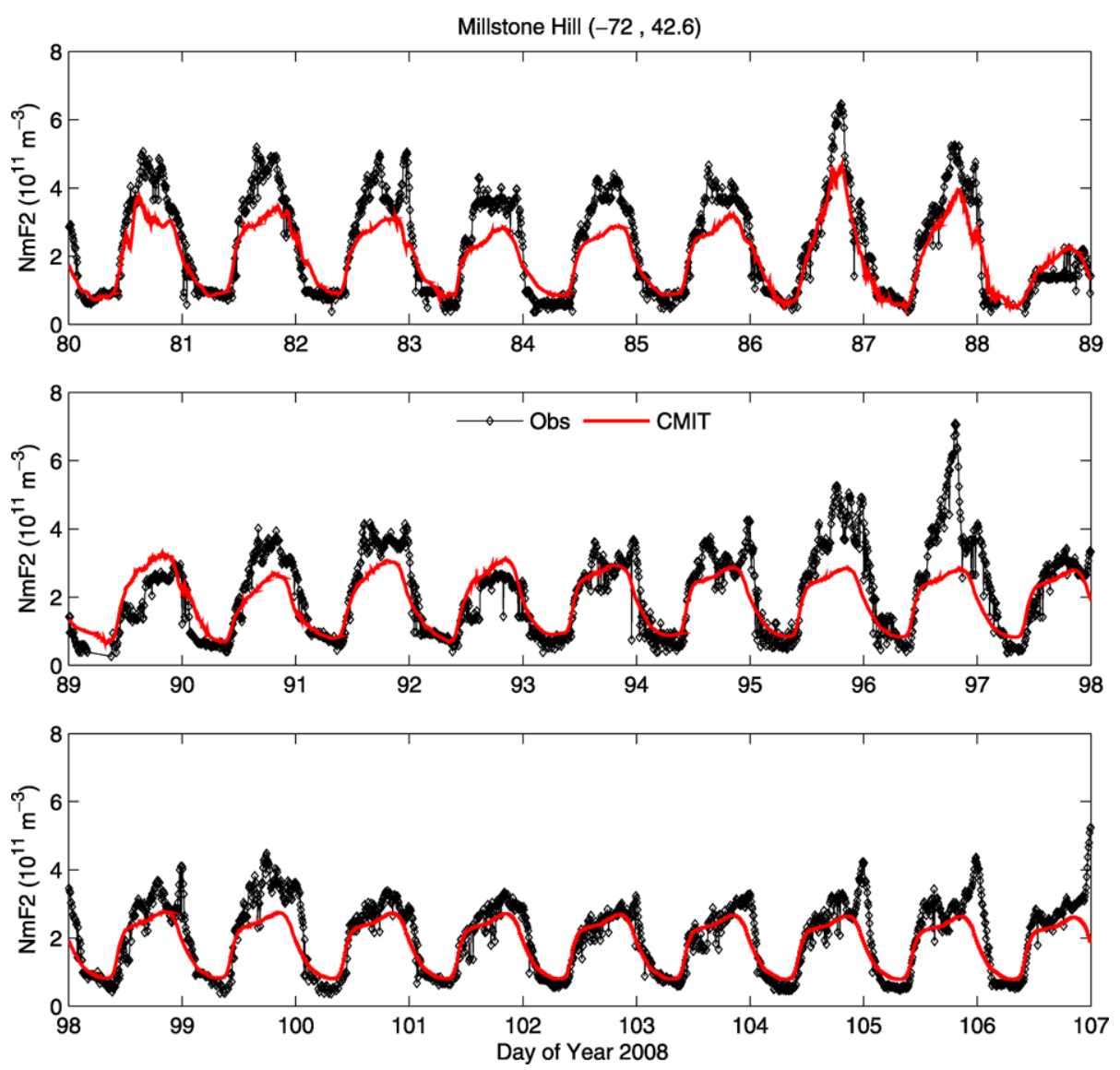

Figure 5 Ionospheric F2 peak densities observed by the ionosonde at Millstone Hill (Black lines with open dots) and the CMIT simulated densities (red lines) during the WHI (DOY 80-107) in 2008.

stations during the WHI. Day-to-day variability is obvious in both the ionosonde data and model results. The most striking feature seen in the observations is the positive response (increase in NmF2) on DOY 86 and DOY 87 and negative response (decrease in NmF2) on DOY 89 and DOY 90. A positive storm effect occurred again on DOY 96 and DOY 97, corresponding to the second CIR event (DOY 96-99) during the WHI. There was no obvious negative storm effect at Millstone Hill following the positive storm effect for the second CIR event. Nevertheless, these positive and negative responses of the ionosphere contributed to the spectral peak at 9 days, as shown in Figure 2 with the spectral analysis. It is also clear that NmF2 changed not just with this 9-day solar-wind driving conditions. There were also days with large electron densities (DOY 80-83, DOY 90-91, and DOY 98 -99) and low electron densities (DOY 92-93, and DOY 101-103) that were not clearly associated with active geomagnetic conditions.

CMIT captured the positive and negative storm responses for the first CIR event (DOY 86 -90) although the absolute magnitude was smaller than that observed. Part of the reason for underestimating the NmF2 could be because the CMIT run for the WHI used a constant $\mathrm{F}_{10.7}$ of 70 , and did not include the big $\mathrm{F}_{10.7}$ burst around DOY 83 (Figure 1). However, the 

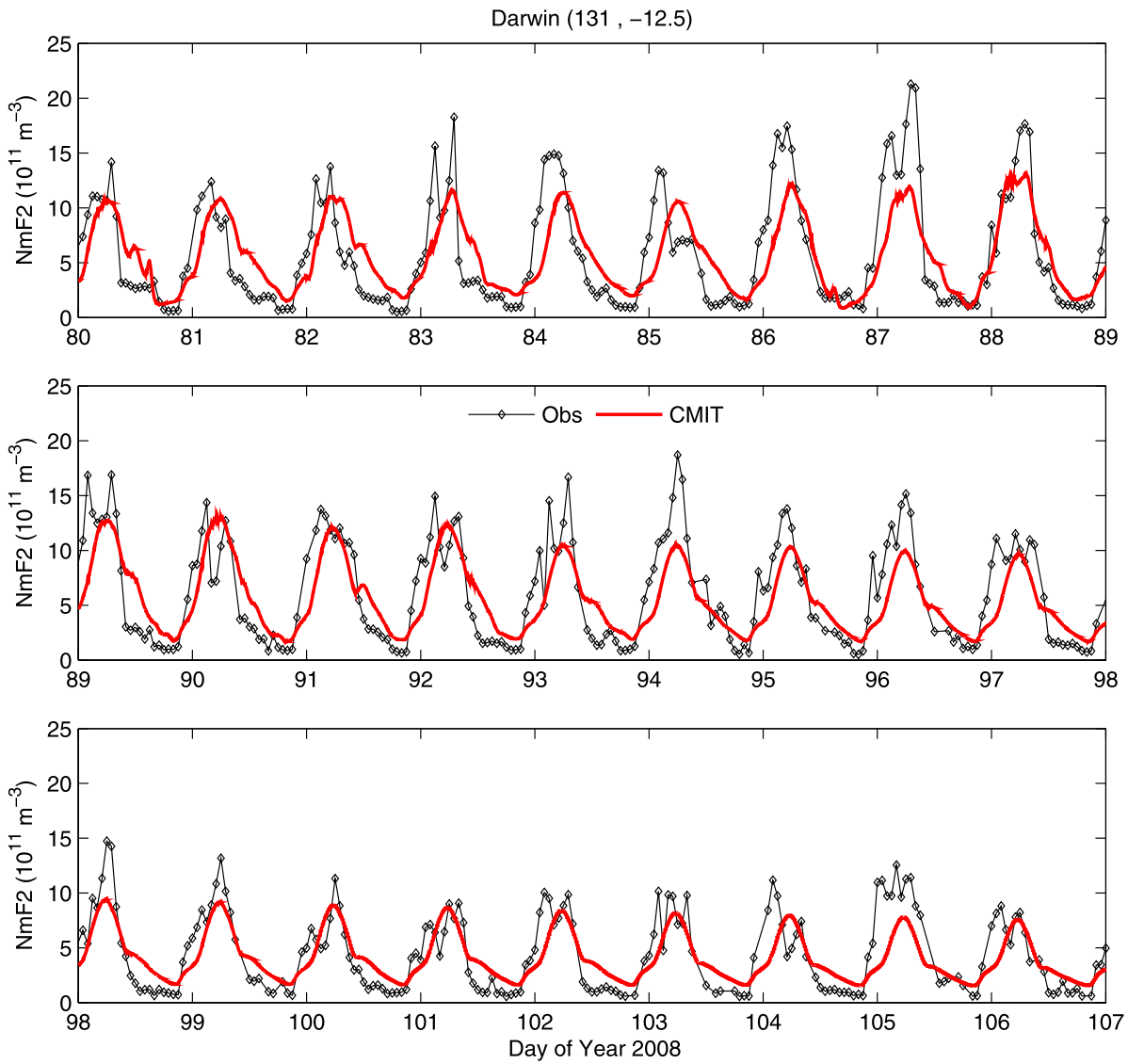

Figure 6 Ionospheric F2 peak densities observed by the ionosonde at Darwin (Black lines with open dots) and the CMIT simulated densities (red lines) during the WHI (DOY 80 - 107) in 2008.

CMIT model also underestimated NmF2 in other days, most noticeably between DOY 80 and DOY 86, between DOY 95 and DOY 96, and on DOY 99. Thus, there must be other factors, besides the constant $\mathrm{F}_{10.7}$ values, that caused the underestimation. Further analysis and improvement of the model are necessary to resolve this issue.

The CMIT missed completely the observed positive response during the second CIR event. The solar-wind speeds were about the same for the first and second events $\left(\approx 600 \mathrm{~km} \mathrm{~s}^{-1}\right)$. However, the IMF $B_{z}$ component was southward during the first event, fluctuating with an amplitude of about $2-4 \mathrm{nT}$, whereas during the second event, IMF $B_{z}$ was mostly northward. Thus, the CMIT model responded stronger to the IMF $B_{z}$ driving than to the high solar-wind speed driving. More modeling work and observations, however, are needed to fully characterize the relative importance of these two parameters during CIR events.

Figure 6 gives ionosonde-observed and CMIT-simulated NmF2 at Darwin, a southern equatorial-anomaly station. Both model and data showed positive response for the first CIR event, with the model again underestimating the magnitude of the positive response. There was no negative response in $\mathrm{NmF} 2$ for the first CIR event, which is different from the case at Millstone Hill. There were also no obvious positive or negative responses for the second 



Figure 7 Ionospheric F2 peak densities observed by the ionosonde at Jicamarca (Black lines with open dots) and the CMIT simulated densities (red lines) during the WHI (DOY 80-107) in 2008.

event in both observations and models. It is also interesting to note that between DOY 81 and DOY 86, as well as on DOY 90 and DOY 91, the diurnal peaks in NmF2, which are produced by solar-EUV radiation, occurred in the morning hours in observations, instead of in the afternoon as predicted by the model. While not shown here, these morning enhancements or afternoon depletions of $\mathrm{NmF} 2$ at Darwin were also not predicted by the empirical IRI model (Bilitza, 2003).

The observed and modeled NmF2 at Jicamarca during the WHI are shown in Figure 7. It appears that there were weak positive responses to the CIR events from DOY 86 to DOY 89, and from DOY 94 to DOY 96, but no noticeable negative effects. The larger bursts of $\mathrm{NmF} 2$ around the dusk in the data on some days (DOY 81, 82, 85, etc.) were caused by the pre-reversal enhancements and may be contaminated by equatorial plasma bubbles. The Jicamarca data also had data gaps. These data gaps and spikes, however, do not affect our spectra from 5 to 27 days since we used 90 days of data in our Lomb-Scargle analysis. CMITsimulated the diurnal changes of the observed NmF2, including the morning and afternoon peaks and noon bite outs (depleted electron densities near local noon), although the model appears to underestimate the magnitudes of both the morning peaks and noon bite outs. 


\section{Discussion}

Lei et al. (2011) showed that the thermospheric-density variations at the periods of 9 and 13.5 days during the solar minimum of 2008 had a very good correlation with high-speed streams/CIRs. The driving mechanisms are the energy deposition at high latitudes during these events which change neutral temperature and global wind circulation, and consequently, neutral composition and density.

The ionospheric response to high-speed streams and CIR events is more complicated, involving the nonlinear coupling of dynamic, chemical, and electrodynamic processes. For instance, penetration electric fields can cause daytime electron density and TEC enhancements at low and middle latitudes during storms (see, e.g., Jakowski et al., 1992; Mannucci et al., 2005; Mendillo, 2006; Lei et al., 2008c; Wang et al., 2010). Traveling atmospheric disturbances produced by the storm-time energy deposition at high latitudes and downwelling of atomic-rich air because of the storm-related changes in neutral-wind circulation can also result in daytime positive responses (Prölss et al., 1991; Prölss, 1993, 1995). The negative storm effects occurred often during the main and recovery phases of storms (Abdu, 1997; Cander and Mihajlovic, 2005). Negative storm effects at high and middle latitudes are caused primarily by neutral composition changes due to the upwelling of molecular-rich air to higher altitudes driven by storm-time enhanced Joule heating (Mayr, Harris, and Spencer, 1978; Burns et al., 1995; Fuller-Rowell et al., 1994). The negative storm effects around the geomagnetic Equator are more closely related to changes in transportation caused by penetration electric fields (Lei et al., 2008c; Wang et al., 2010), as well as changes in neutral composition at later times during strong storms (Prölss, 1995; Buonsanto, 1999).

The periodicities seen in the ionospheric peak density between DOY 50 and DOY 140, which also include the WHI, appear to be the results of all these processes. The negative storm effect at Millstone Hill (Figure 5) for the first CIR event during the WHI was probably related to changes in neutral composition caused by the upwelling of molecular-rich air to higher altitudes and the transportation of this air to lower latitudes by neutral-wind circulation. The lack of negative storm effects at lower latitudes may be because that CIRdriven storms are weak so that the perturbation of neutral composition is likely to be very small and thus less effective in reducing electron densities. It is also possible that the transport processes caused by neutral winds and penetration electric fields balance out the effect of chemical process resulting in relatively small changes in electron densities. Penetration electric fields are usually eastward during daytime which leads to an upward drift of the plasma to effectively reduce the molecular recombination effect. The equatorward meridional neutral winds can also move the plasma to higher latitudes and enhance the electron density.

It appears that changes in solar-wind speed were the major reason for the enhanced geomagnetic activity during the study period (DOY 50 to DOY 140 in 2008) as both had dominant spectral peaks with 9- and 13.5-day periods. The IMF $B_{z}$ component consisted mainly of a 7-day periodicity. However, the magnitude of the IMF $B_{z}$ variations was small $(\approx 2 \mathrm{nT})$. Thus, the effect of the IMF $B_{z}$ component was primarily on high-latitude electric fields and penetration electric fields.

The ionospheric responses at different latitudes were different. At middle latitudes, all stations showed variations in power present peaking at 13.5, 9, 7, and 5 days, indicating that both solar-wind and IMF $B_{z}$ were effective in producing changes in the ionosphere at this latitude. The fact that 13.5- and 9-day spectral peaks were the dominant components suggests that solar-wind drivers were the more effective sources of these periodicities. 
At the magnetic Equator, both stations showed 13.5-, 9-, 7-, and 5-day spectral peaks. The 7-day period peak appeared to be stronger than the 9-day peak, suggesting that penetration electric field could play a significant role at the magnetic Equator in changing electron densities since there was a relatively large 7-day spectral peak in the IMF $B_{z}$ component, but there were no significant peak signatures of the same period in both the solar-wind speed and the Kp index. Variations in IMF $B_{z}$ conditions cause variations in high-latitude electric fields. These high-latitude electric fields can then penetrate to middle and lower latitudes since the shielding effect of the Region 2 currents is not effective under these conditions (see, e.g., Richmond, Peymirat, and Roble, 2003; Huang, Foster, and Kelley, 2005; Wang et al., 2008a). The penetration electric field causes changes in the vertical drifts of the ionosphere and thus affects ionospheric plasma densities (see, e.g., Lei et al., 2008c; Wang et al., 2010). This is especially the case for CIR and high-speed stream events when the IMF $B_{z}$ component tends to fluctuate with time as shown in Figure 1. The 5-, 9-, and 13.5-day spectral peaks appeared to be the results of magnetic activity as there were also peaks of the same periods in geomagnetic activity (Kp index). However, the 9-day spectral peak was caused mostly by solar-wind speed and density changes, whereas 5- and 13.5-day spectral peaks were the results of changes in solar-wind speed, density, and IMF $B_{z}$.

The response of the ionosphere during the WHI in the equatorial anomaly region was more complicated. 13.5-, 7-, and 5-day spectral peaks were suppressed at all three stations, leaving the 9-day peak as the only evident spectral peak that was also seen in solar-wind and IMF drivers. Since spectral peaks of 13.5-, 9-, 7-, and 5-day periods were seen near the magnetic Equator, which most likely were the result of penetration electric fields that were caused by the variations in IMF $B_{z}$, it is expected that in the equatorial-anomaly region spectral peaks with the same periods would also occur as penetration electric fields should have similar effects on the ionosphere in this region. There could be a number of processes, chemical, transportation, and penetration electric fields, and their nonlinear interactions playing important roles in determining the ionospheric response to CIR events. Further investigations are needed to fully understand the cause of the different ionospheric responses seen in this region (Burns et al., 2007).

There was also an 11-day periodicity in $\mathrm{NmF} 2$ at equatorial-anomaly stations. This periodicity may be related to the variations of the same period in solar-wind density around the WHI. Huang, Foster, and Erickson (2002) showed that changes in solar-wind dynamical pressure can cause changes in electric fields and thus variations of global F2 peak electron densities. It is also possible that the periodicity was the results of the nonlinear interaction of the variations of different periods, such as the 9-day and 13.5-day variations. They might also be related to the lower-atmospheric planetary waves that propagate upward to the mesosphere and lower-thermosphere region causing changes in the ionosphere (LópezGonzález et al., 2009). In fact, Liu et al. (2010) showed, using model simulations, that stationary planetary waves can modify semidiurnal tides which, in turn, produce changes in the neutral-wind dynamo and introduce periodicities in the ionospheric peak density and total-electron content that have the same periods as those of the planetary waves.

The 16-21 day spectral peak in the ionosonde data at multiple stations could be related to lower atmospheric-planetary waves. Forbes et al. (1995) and Luo et al. (2002) showed observational evidence that there is quasi-16-day periodicity in the mesosphere and lowerthermosphere region. Vineeth et al. (2007) showed that quasi-16-day wave from the lower atmosphere can affect equatorial electrojets and neutral-wind dynamo field at the magneticdip Equator, which can then cause perturbations to the ionosphere. In fact, spectral peaks of other periods seen during the WHI may also be mixed with the effect of planetary waves. To fully understand the global behavior of the ionospheric day-to-day variability during CIR 
events, observations both in the ionosphere and lower atmosphere, as well as physics-based modeling, are needed.

The CMIT model run for the WHI shows promising results for the first CIR event, capturing both the positive and negative storm effects that occurred at middle latitudes. The model results also show day-to-day variability in the ionospheric F peak density. The model, however, did not reproduce the observed positive storm effect during the second CIR event. It seems that the model did not respond strongly to the changes in solar-wind speed. In addition, the model run for the WHI did not include any planetary-wave perturbations at the model lower boundary. We will include these perturbations in future studies to understand the effect of these waves on the ionosphere.

\section{Conclusions}

Ionospheric F2 peak electron densities measured at ten ionosonde stations were used to investigate ionospheric day-to-day variability around and throughout the WHI in 2008. The ionosonde data characteristically showed that there was significant global day-to-day variability in NmF2. This variability had 5-, 7-, 9-, and 13.5-day periodicities, which were related to the same periodicities in the high-speed solar-wind streams and IMF. At middle latitudes, the ionosphere appeared to respond directly to the solar-wind/geomagnetic activity forcing at high latitudes, with the day-to-day variability having similar spectral peaks as those in solar-wind and geomagnetic activity. At the geomagnetic Equator, the ionosphere had a 7-day periodicity, indicating that this spectral peak was related to the peak in the IMF $B_{z}$ component with the same period. In the equatorial-anomaly region, the ionosphere showed more complicated day-to-day variability with the 9-day periodicity being the dominant mode, suggesting the interplay of nonlinear interactions of different ionospheric processes in these regions. In addition, there were periodicities of 11 and 16-21 days in the ionosphere at some stations.

The CMIT model was run using the observed solar-wind and IMF data during the WHI as the model driver. The CMIT simulations show daily variability in ionospheric peak electron densities. The model also captured the positive and negative responses of the ionosphere at middle latitudes during the CIR event in WHI. The response of the model to the second CIR event was relatively weak when compared to observations.

Acknowledgements This article is based upon work supported by NASA grants NNX08AQ91G and NNH08AH37I, and by the Center for Integrated Space Weather Modeling (CISM) which is funded by the STC Program of the National Science Foundation under Agreement Number ATM-0120950. The National Center for Atmospheric Research is sponsored by the National Science Foundation. One of the authors (JL) would like to acknowledge support provided by NASA grant NNX10AE62G and AFOSR MURI Award FA9550-07-1-0565. This work is also supported by the National Science Foundation of China (40828003).

\section{References}

Abdu, M.A.: 1997, Major phenomena of the equatorial ionosphere-thermosphere system under disturbed conditions. J. Atmos. Solar-Terr. Phys. 59, $1505-1519$.

Altadill, D., Apostolov, E.M.: 2003, Time and scale size of planetary wave signatures in the ionospheric F region. Role of the geomagnetic activity and mesosphere/lower thermosphere winds. J. Geophys. Res. 108, 1403. doi:10.1029/2003JA010015.

Bilitza, D.: 2003, International reference ionosphere 2000: Examples of improvements and new features. Adv. Space Res. 31, $757-767$.

Buonsanto, M.J.: 1999, Ionospheric storms-a review. Space Sci. Rev. 88, 563 -601. 
Burns, A.G., Killeen, T.L., Deng, W., Carignan, G.R., Roble, R.G.: 1995, Geomagnetic storm effects in the low-latitude to middle-latitude upper atmosphere. J. Geophys. Res. 100, $14673-14691$.

Burns, A.G., Solomon, S.C., Wang, W., Killee, T.L.: 2007, The ionospheric and thermospheric response to CMEs: Challenges and successes. J. Atmos. Solar-Terr. Phys. 69, $77-85$.

Cander, L.R., Mihajlovic, S.J.: 2005, Ionospheric spatial and temporal variations during the 29-31 October 2003 storm. J. Atmos. Solar-Terr. Phys. 67, $1118-1128$.

Codrescu, M.V., Fuller-Rowell, T.J., Foster, J.C.: 1995, On the importance of E-field variability for Joule heating in the high-latitude thermosphere. Geophys. Res. Lett. 22, $2393-2396$.

Forbes, J.M., Palo, S., Zhang, X.: 2000, Variability of the ionosphere. J. Atmos. Solar-Terr. Phys. 62, 685693.

Forbes, J.M., Hagan, M.E., Miyahara, S., Vial, F., Hanson, A.H., Meek, C.E., Portnyagin, Y.I.: 1995, Quasi 16-day oscillation in the mesosphere and lower thermosphere. J. Geophys. Res. 100, 9149-9163.

Fuller-Rowell, T.J., Codrescu, M.V., Moffett, R.J., Quegan, S.: 1994, Response of the thermosphere and ionosphere to geomagnetic storms. J. Geophys. Res. 99, 3893-3914.

Gibson, S.E., Kozyra, J.U., de Toma, G., Emery, B.A., Onsager, T., Thompson, B.J.: 2009, If the Sun is so quiet, why is the Earth ringing? A comparison of two solar minimum intervals. J. Geophys. Res. 114, A09105. doi:10.1029/2009JA014342.

Horne, J.H., Baliunas, S.L.: 1986, A prescription for period analysis of unevenly sampled time series. Astrophys. J. 302, $757-763$.

Huang, C.-S., Foster, J.C., Erickson, P.J.: 2002, Effects of solar wind variations on the midlatitude ionosphere. J. Geophys. Res. 107, 1192. doi:10.1029/2001JA009025.

Huang, C.-S., Foster, J.C., Kelley, M.C.: 2005, Long-duration penetration of the interplanetary electric field to the low-latitude ionosphere during the main phase of magnetic storms. J. Geophys. Res. 110, A11309. doi:10.1029/2005JA011202.

Jakowski, N., Jungstand, A., Schlegel, K., Kohl, H., Rinnert, K.: 1992, The ionospheric response to perturbation electric-fields during the onset phase of geomagnetic storms. Can. J. Phys. 70, 575-581.

Lei, J., Thayer, J.P., Forbes, J.M., Sutton, E.K., Nerem, R.S., Temmer, M., Veronig, A.M.: 2008a, Global thermospheric density variations caused by high-speed solar wind streams during the declining phase of solar cycle 23. J. Geophys. Res. 113, A11303. doi:10.1029/2008JA013433.

Lei, J., Thayer, J.P., Forbes, J.M., Wu, Q., She, C., Wan, W., Wang, W.: 2008b, Ionosphere response to solar wind high-speed streams. Geophys. Res. Lett. 35, L19105. doi:10.1029/2008GL035208.

Lei, J., Wang, W., Burns, A.G., Solomon, S.C., Richmond, A.D., Wiltberger, M., Goncharenko, L.P., Coster, A., Reinisch, B.W.: 2008c, Observations and simulations of the ionospheric and thermospheric response to the December 2006 geomagnetic storm: Initial phase. J. Geophys. Res. 113, A01314. doi:10.1029/2007JA012807.

Lei, J., Thayer, J.P., Wang, W., McPherron, R.L.: 2011, Impact of CIR storms on thermosphere density variability during the solar minimum of 2008. Solar Phys. doi:10.1007/s11207-010-9563-y.

Liu, H.-L., Wang, W., Richmond, A.D., Roble, R.G.: 2010, Ionospheric variability due to planetary waves and tides for solar minimum conditions. J. Geophys. Res. 115, A00G01. doi:10.1029/2009JA015188.

Lomb, N.R.: 1976, Least-squares frequency analysis of unequally spaced data. Astrophys. Space Sci. 39, $447-462$.

López-González, M.J., Rodríguez, E., García-Comas, M., Costa, V., Shepherd, M.G., Shepherd, G.G., Aushev, V.M., Sargoytchev, S.: 2009, Climatology of planetary wave type oscillations with periods of 2-20 days derived from $\mathrm{O} 2$ atmospheric and $\mathrm{OH}(6-2)$ airglow observations at mid-latitude with SATI. Ann. Geophys. 27, $3645-3662$.

Luhmann, J.G., Solomon, S.C., Linker, J.A., Lyon, J.G., Mikic, Z., Odstrcil, D., Wang, W., Wiltberger, M.: 2004, Coupled model simulation of a Sun-to-Earth space weather event. J. Atmos. Solar-Terr. Phys. 66, $1411-1424$.

Luo, Y., Manson, A.H., Meek, C.E., Thayaparan, T., MacDougall, J., Hocking, W.K.: 2002, The 16-day wave in the mesosphere and lower thermosphere: Simultaneous observations at Saskatoon $\left(52^{\circ} \mathrm{N}, 107^{\circ} \mathrm{W}\right)$ and London $\left(43^{\circ} \mathrm{N}, 81^{\circ} \mathrm{W}\right)$, Canada. J. Atmos. Solar-Terr. Phys. 64, 1287-1307. doi:10.1016/S13646826(02)00042-1.

Lyon, J.G., Fedder, J.A., Mobarry, C.M.: 2004, The Lyon-Fedder-Mobarry (LFM) global MHD magnetospheric simulation code. J. Atmos. Solar-Terr. Phys. 66, $1333-1350$.

Mannucci, A.J., Tsurutani, B.T., Iijima, B.A., Komjathy, A., Saito, A., Gonzalez, W.D., Guarnieri, F.L., Kozyra, J.U., Skoug, R.: 2005, Dayside global ionospheric response to the major interplanetary events of October 29-30, 2003 "Halloween Storms". Geophys. Res. Lett. 32, L12S02. doi:10.1029/2004GL021467.

Mayr, H.G., Harris, I., Spencer, N.W.: 1978, Some properties of upper-atmosphere dynamics. Rev. Geophys. Space Phys. 16, $539-565$. 
Mendillo, M.: 2006, Storms in the ionosphere: Patterns and processes for total electron content. Rev. Geophys. 44, RG4001. doi:10.1029/2005RG000193.

Mursula, K., Zieger, B.: 1996, The 13.5-day periodicity in the sun, solar wind, and geomagnetic activity: The last three solar cycles. J. Geophys. Res. 101, 27077-27090.

Prölss, G.W.: 1993, Common origin of positive ionospheric storms at middle latitudes and the geomagnetic activity effect at low latitudes. J. Geophys. Res. 98, 5981-5991.

Prölss, G.W.: 1995, Ionospheric F-region storms. In: Volland, H. (ed.) Handbook of Atmospheric Electrodynamics 2, CRC Press, Boca Raton, $95-248$.

Prölss, G.W., Brace, L.H., Mayr, H.G., Carignan, G.R., Killeen, T.L., Klobuchar, J.A.: 1991, Ionospheric storm effects at subauroral latitudes-a case study. J. Geophys. Res. 96, 1275 - 1288.

Richmond, A.D., Ridley, E.C., Roble, R.G.: 1992, A thermosphere/ionosphere general circulation model with coupled electrodynamics. Geophys. Res. Lett. 19, $601-604$.

Richmond, A.D., Peymirat, C., Roble, R.G.: 2003, Long-lasting disturbances in the equatorial ionospheric electric field simulated with a coupled magnetosphere-ionosphere-thermosphere model. J. Geophys. Res. 108, 1118. doi:10.1029/2002JA009758.

Rishbeth, H., Mendillo, M.: 2001, Patterns of ionospheric variability. J. Atmos. Solar-Terr. Phys. 63, $1661-$ 1680.

Scargle, J.D.: 1982, Statistical aspects of spectral analysis of unevenly spaced data. Astrophys. J. 263, 835 853.

Tsurutani, B.T., Gonzalez, W.D., Gonzalez, A.L.C., Tang, F., Arballo, J.K., Okada, M.: 1995, Interplanetary origin of geomagnetic activity in the declining phase of the solar cycle. J. Geophys. Res. 100, $21717-$ 21733.

Tsurutani, B.T., Gonzalez, W.D., Gonzalez, A.L.C., Guarnieri, F.L., Gopalswamy, N., Grande, M., Kamide, Y., Kasahara, Y., Lu, G., Mann, I., McPherron, R., Soraas, F., Vasyliunas, V.: 2006, Corotating solar wind streams and recurrent geomagnetic activity: A review. J. Geophys. Res. 111, A07S01. doi:10.1029/2005JA011273.

Vineeth, C., Pant, T.K., Devasia, C.V., Sridharan, R.: 2007, Atmosphere-ionosphere coupling observed over the dip equatorial MLTI region through the quasi 16-day wave. Geophys. Res. Lett. 34, L12102. doi:10.1029/2007GL030010.

Wang, W., Wiltberger, M., Burns, A.G., Solomon, S.C., Killeen, T.L., Maruyama, N., Lyon, J.G.: 2004, Initial results from the CISM coupled magnetosphere-ionosphere-thermosphere (CMIT) model: thermosphere ionosphere responses. J. Atmos. Solar-Terr. Phys. 66, $1425-1442$.

Wang, W., Lei, J., Burns, A.G., Wiltberger, M., Richmond, A.D., Solomon, S.C., Killeen, T.L., Talaat, E.R., Anderson, D.L.: 2008a, Ionospheric electric field variations during a geomagnetic storm simulated by a coupled magnetosphere ionosphere thermosphere (CMIT) model. Geophys. Res. Lett. 35, L18105. doi:10.1029/2008GL035155.

Wang, W., Burns, A.G., Wiltberger, M., Solomon, S.C., Killeen, T.L.: 2008b, Altitude variations of the horizontal thermospheric winds during geomagnetic storms. J. Geophys. Res. 113, A02301. doi:10.1029/ 2007JA012374.

Wang, W., Lei, J., Burns, A.G., Solomon, S.C., Wiltberger, M., Xu, J., Zhang, Y., Paxton, L., Coster, A.: 2010, Ionospheric response to the initial phase of geomagnetic storms: 1. Common features. J. Geophys. Res. 115, A07321. doi:10.1029/2009JA014461.

Weber, M.A., Acton, L.W., Alexander, D., Kubo, S., Hara, H.: 1999, A method for characterizing rotation rates in the soft X-ray corona. Solar Phys. 189, 271-288.

Wiltberger, M., Wang, W., Burns, A.G., Solomon, S.C., Lyon, J.G., Goodrich, C.C.: 2004, Initial results from the coupled magnetosphere ionosphere thermosphere model: magnetospheric and ionospheric responses. J. Atmos. Solar-Terr. Phys. 66, $1411-1424$.

Xiong, J., Wan, W., Ning, B., Liu, L., Gao, Y.: 2006, Planetary wave-type oscillations in the ionosphere and their relationship to mesospheric/lower thermospheric and geomagnetic disturbances at Wuhan $(30.61 \mathrm{~N}$, 114.51E). J. Atmos. Solar-Terr. Phys. 68, $498-508$. 